\title{
STUDY ON THE STANDARD ARCHITECTURE FOR GEOINFORMATION COMMON SERVICES
}

\author{
ZHA Zhuhua ${ }^{\mathrm{a}}$, ZHANG Libo ${ }^{\mathrm{b}}$, WANG Cong ${ }^{\mathrm{a}}$, JIANG Jie ${ }^{\mathrm{a}}$, HUANG Wei ${ }^{\mathrm{a}}$, \\ a.National Geomatics Center of China, Beijing 100830, China,(zhazh, jjie, huangwei, zhanghongping, - \\ wangcong)@nsdi.gov.cn \\ b National Quality Inspectioin and Testing Center for Surveying and Mapping Products, 37856062@qq.com
}

Commission IV

KEY WORDS: Standard, Serivce, Geoinformation Common Services, Standard Architecture,

\begin{abstract}
:
The construction of platform for geoinformation common services was completed or on going in in most provinces and cities in these years in China, and the platforms plays an important role in the economic and social activities . Geoinfromation and geoinfromation based services are the key issues in the platform .The standards on geoinormation common services play as bridges among the users, systems and designers of the platform. The standard architecture for geoinformation common services is the guideline for designing and using the standard system in which the standards integrated to each other to promote the development, sharing and services of geoinformation resources.

To establish the standard architecture for geoinformation common services is one of the tasks of 'Study on important standards for geonformation common services and management of public facilities in city'. The scope of the standard architecture is defined, such as data or information model, interoperability interface or service, information management. Some Research work on the status of international standards of geoinormation common services in organization and countries, like ISO/TC 211, OGC and other countries or unions like USA、EU、Japan have done. Some principles are set up to evaluate the standard, such as availability, suitability and extensible ability. Then the development requirement and practical situation are analyzed, and a framework of the standard architecture for geoinformation common services are proposed.

Finally, a summary and prospects of the geoinformation standards are made.
\end{abstract}

\section{INTRODUCTION}

\subsection{National Platform for Common Geospatial Information Services}

The National Platform for Common GeoSpatial Information Services, which is also known as TIANDITU, is the website providing "one-stop" geospatial information services to personal users, enterprises, professional agencies and governments via networks such as Internet, mobile communication network, Intranet, etc. It is created by National Administration of Surveying, Mapping and Geoinformation of China (NASG) as an important part of the geospatial framework for digital China aims at promoting the geographic information resources sharing, and improving the ability and efficiency for services.

Website users can browse maps, locate places, measure distances or areas, plan car driving routes, while professional users can access various TIANDITU's service resources via standardized interfaces for value-added services and applications. TIANDITU also provides many Application Programming Interfaces (APIs) to facilitate the integration of its service resources and various systems or websites. With these standardized interfaces and APIs the users can avoid the chaos for handling, maintenance and updating the base maps and focus on their own thematic data and applications. Thus decrease the development and research cost for providing commercial or professional applications.

\subsection{Standard and Standard Architecture}

The construction of TIANDITU was completed or on going in in most provinces and municipalities in these years, the platforms plays an important role in the economic and social activities . Geoinfromation and geoinfromation based services are the key issues in the platform .The standards on geoinormation common services play as bridges among the users, systems and designers of the platform. The standard architecture for geoinformation common services is the guideline for designing and using the standard system in which the standards integrated to each other to promote the development, sharing and services of geoinformation resources.

\section{REVIEW OF STANDARDIZATION OF GEOINFORMATION COMMON SERVICES WORK}

\subsection{International Development}

The development of international standards geographic information industry is growing very rapidly, every country takes the standards very seriously, and takes close cooperation in the research of geographic information standardization and creating standards. International standardization of geographical 
information can be roughly divided into two parts. One is taking the existing information technology (IT) standards, directly or indirectly using the other is the development of geographic information-oriented features of the standard, including data definitions, data description, data processing and other aspects of shared services . Like other standards, geographic information standards are divided into five levels, namely international standards, regional standards, national standards, local standards and other standards(Figure 1).

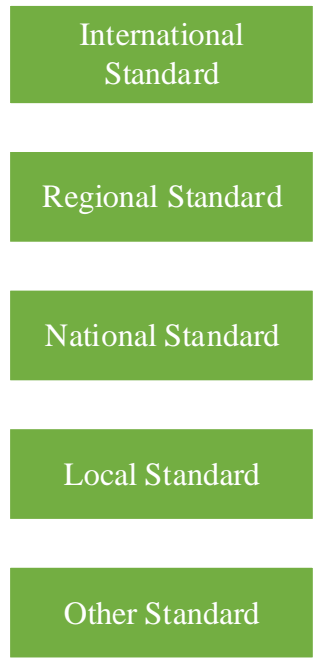

\section{National Standard}

\section{Industry Standard}

Local Standard

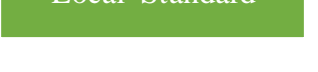

Enterprise Standard

\section{International Standard Level Chinese Standard Level}

Figure 1 Standard Level

International Standardization Organization / Technical Committee 211 (ISO/TC211), and international organization for standardization forum on geographic information which with Open Geospatial Consortium(OGC) as the representative, and other regional standardization organization on geographic information like CEN/TC 287, established the complete reference model, researched and developed a set of high-tech applied standards or specifications with the active participation of members.

The main objective of ISO/TC211 located in the geographic information data and service standards, developed a series of standards around the standards' quality and conformance testing. Its scope of work is the field of digital geographic information standardization. Its main task is to develop a structured definition, description and management system standard geographic information (series standard No. ISO 19100), which is directly or indirectly related to the target location on the planet or phenomena information. They describes the management of geographic information methods, tools and services, including data definitions, descriptions, acquisition, processing, analysis, accessing, representing, and data conversion methods, processes and services. in digital / electronic form between different users, different systems and different places. So it can realize the interoperability of geographic information systems, including interoperable distributed computing environment. With the rapid development of high technology, recently proposed a number of goals for mobile, location-based services based on geographic information standards, navigation technology, sensor webs and other hot spots technology.

Other international standardization on geographic information : International Hydrographic Organization (IHO) have published the S52, DX90 (S-57), S60 and other standards, they describes the digital hydrographic data generation, expression, and quality evaluation criteria in detail. The Technical Committee under International Cartographic Association (ICA) is also actively involved in Geographic Information Standards.

\subsection{Local Development in}

Geographic information and geographic information common services has been widely used in the national economy, security and public life, and gradually formed geographic information services industry by the geographic information common service including elements of geographic information, services and platform. Standardization of geographic information common services in China has achieved great development.

There are four levels of standards in China: national standards, industry standards, local standards and enterprise standards(Figure 1). Under the provisions of "People's Republic of China Standardization Law": Industry standards are approved by the ministry department and the Commission (Council) within the scope of the department consistent use. For example: machinery, electronics, construction, chemical industry, metallurgy, light industry, textile, transportation, energy, agriculture, forestry, water conservancy, etc., all have developed their own industry standard.

Since 1983, the system research of geographic information in China began, and published "Research Report on National Standard and Specification of Resources and Environment Information System" next year. It is the first theory research report about the standardization of geographic information in China, and has a significant impact on the later standardization word of geographic information system. A number of geographic information standard were developed and published in China in these 30 years, and some qualified person of different level were trained to devote themselves to the geographic information standard career. China has conducted a preliminary exploration of the geographic information standard before Ninth Five-Year Plan. With the increasing informatization, however, the focus of geographic information standard transferred to the field of geographic information sharing after Ninth Five-Year. Some urgent standards such as constructing national spatial information infrastructure, digital region (Digital China, Digital Industry, Digital Cities, Digital Community) were involved. When stepping in "Tenth Five-Year Plan"period, all industries relating geographic information have attached importance to the standardization work. China has classed satellite navigation and positioning applications as major project, and carrying out the research on "Traffic geographical information platform and positioning technology" combining with intelligent transportation system. Moreover, the project of the global satellite positioning system industrialization has been approved. The network space information standards and sharing application service which belongs to State 863 Project has generated amounts of national and industry standards. And the progress above has accelerated development of the geographic information career. 
During the Eleventh Five-Year, China has enacted "Five-year Development Plan of National geographic informatization". The whole steps of forming a standard has made achievements in preliminary study, enacting or revising standard, system study, broadcasting and implement, employing. According to the requirements "Five-year Development Plan of National geographic informatization", the national geographic information standardization technical committee organized and arranged the compilation of "National geographic information standard system". And this work has two stages, firstly, compiling the "framework of National geographic information standard system". Then, with the completion of framework, forming the "National geographic information standard system"

"National Standard System of Geoinformation" published in 2009, as the guideline for project approval and development of future geoinformation national standard, is of great significance for promotion of geoinformation industry development and accelerate the construction of digital china. It promoted a set of standards for definition, description and management of geonformation standards, described the content, postioning and reloationship, cleared the classification, structure and level for national standards of geoinformation. It consisted of 7 classes, 44 subclasses and 219 standards, devided to three levels: basic class, professtional class and special class.

National geographic information common service platform has also been launched during the $11^{\text {th }}$ Five-Year,. Meanwhile, some new trends of standardization work began, for example: the standardization is converting from GIS data to geographic information service.

"The 12th Five-year Plan of Surveying, Mapping and Geoinformation Standardization" made it clear that to fulfil the zero breakthrough from national standard to international standard. On March 2012, "Geographic information -- Content components and encoding rules for imagery and gridded data" (ISO/WD TR19163)was proposed to ISO/TC211, and now it is under development on Working Draft.

Based on the classification of attributes, spatial types and senser types, the standard describes the needed content components for imagery and grided data, define data structure and encoding rules for mapping the content to the data structure. The project implementation time is from Nov.7 2012 to Nov. 7, 2015.

\section{STUDY ON STANDARD ARCHITECTURE FOR GEOINFORMATION COMMON SERVICES}

\section{1 scope}

Geoinformation common services standard system consists of the standards which support universal development and application service in geoinformation fields. The feature of the standard system to geoinformation standards is to support geoinformation common services platform applications, and focus on geographic information data resources, service ability, application and construction for the common services platform.

\section{2 methodology}

ISO / TC 211 used concepts and methods of software engineering, take the Unified Modeling Language (Unified Modeling Language, UML) as its standard conceptual schema language, to plan and build international standard reference model and a series of geographic information standards, and achieved good results. In China, the hierarchical chart and sequence chart are commonly used method to build a standard system architecture, it can make classification and grading with their own level, grade, types, function, profession and other properties, or, it can be devided by the standardized object life cycle, so it becomes a general process for building standards system tables.

So, this standard system architecture were made under the guiding of system engineering theory, used UML static chart to express the architecture and inherent logical relationship of geoinformation common services.

Geoinformation common services is a complete procedure of information system integration and applying consisting of geoinformation data, services, construction and application, it has a positive effect for clearing internal information flow by using UML to build the standard system architecture.

The architecture result show in Figure 2.

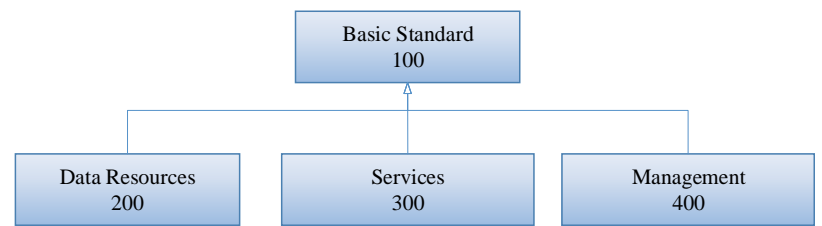

Figure 2 Architecture of geoinforamtion common services standards

\subsection{Components of the standard architecture}

\section{Basic Standard}

Base standard provides technology framework for geoinformation common services standardization, it gives the reference standard collection when develop related standards, includeing 4 subclass: reference models, terminology, reference system and schema framework.

\section{Data Resources}

This class takes account the content, access, representation, maintenance of geoinformation common services, and gives the definition standard for data content, classification and representation.

\section{Mangement}

This class provides system model for building geoinformation common services management, it gives the subclass about construction requirements, management specification , design and construction specification of application system and the platform.

\section{Developing Suggestion}

The data resources standard(200) involve multiple types of data resources, including geographic entity data, places and address data, the electronic map data, image data, elevation data, volunteers geographic data, street view data and so on. Data classification, collection, production, publishing and other aspects of the process required the relevant standards. "Common Geographic Information Classification and Code",

" Volunteer Geoinformation Data : Classification and Acquisition Specification", "Common Geographic Framework Data: Specification of Electronic Map on Mobile" , related on the foundation of geoinformation common services, or actually developing in industry, should listed as the first class standards. 
Part of Service standards are mature and widely used in industry, they are usually OGC standards or ISO standards. Although many OGC standards have widely used in fact, such as WFS, WPS, WMTS services, but the process converting to Chinese national standards is still slow, need continue to advance. Such standards, like "Geographic Information: Web Feature Service"," Geographic Information: Web Coverage Service", "Geographic information - Simple Feature Access, refer to ISO 19142, OGC WCS, ISO 19125, which has been tested in industry, the main work is standard adoption. Tile map service can refer OGC WMTS service standard, which was released version 1.0.0 in 2010, has made widely used at home and abroad, the national, provincial and municipal TIANDITU nodes widely used WMTS standard as the standardized map tile service. These standards should be the first class standards.

\section{CONCLUSION \& CHALLENGES}

This article relies on the "Important Standard Research for Urban Geographic Information Common Services and Municipal Facilities Management" project which is belong to Public Welfare Scientific Research Project of General Administration of Quality Supervision, Inspection and Quarantine of the R.P.C.(GAQSIQPRC), under the objective for development and use of geographic information common service, propose geographic information common services standard architecture and proposal for development.

Geoinformation common services, just like GIS, has the features like multi-technology crossing, multi-industry fields, etc. Therefore, to promote the construction of geoinformation common services platform and implementation of geoinformation common services, we need use the standardization theory as the guideline, innovate existing management and working mechanism of standardization, emphasis enterprise position in development of standard, promote the integration of standardization work among different industry, and multi-technology integration.

\section{REFERENCES}

National Standardization Technial Committee of Geomatics, 2007, National Standard Architecture for Geoinformation HUANG Qian. WANG Erqi, LIANG Jun. Preliminary Research on the Standard System of Geographic Information System, Journal of Geo-information Science, 2013(3):362-368

YU Xu, ZHANG Xingfu, et. Review on geographic information standardization in China, Engineering on Surveying and Mapping, 2010(6):1-3

WANG Chunqing, HE Junfang, ZHANG Qiuyi,et. Research on the Framework of Standards System for Geographic Information Navigation and Location Services. Standardization of Surveying and Mapping, 2013(2):1-5

ZHU Xiuli, LI li. The Development of Geographic Information Standard System by Means of UML. Bulletin of Surveying and Mapping, 2012(4):33-37

BAI Yi. Research on Standardization System Management and Standards Modularization in Geographic Information. Ph.D. Dissertation

MA Shengnan, WEI Hong, LIU Bisong. Review and Consideration of Progress in Geographic Information Standardization at Home and Abroad. Geomatics and information science of Wuhan University. 2008(9):886-891
MIAO Qianjun. Push the construction of Geomatics Public Services Platform Forward. Geomatics World. 2010(1):6-11 ZHAO Xin, DENG Guoqing, DUAN Yihong, LU Yuxia. On Conformance Test for standards of Surveying, Mapping and Geoinformation - Theory and Technical Method. Standardization of Surveying and Mapping. 2013(4):1-4

ZENG Wenhua. On Geographic Information Standard System Framework in Zhejinag Province. Standardization of Surveying and Mapping. 2013(4):5-8 